\title{
Endoscopic Extraction of a Retained Surgical Drain after Esophagectomy
}

\author{
Rui Morais $^{\mathrm{a}}$ Marco Silva $^{\mathrm{a}}$ Andreia Albuquerque $^{\mathrm{b}}$ Filipe Vilas-Boas $^{\mathrm{a}}$ \\ Pedro Pereira $^{a}$ Guilherme Macedo ${ }^{a}$ \\ ${ }^{a}$ Gastroenterology Department - Centro Hospitalar de São João, Porto, Portugal; ' ${ }^{b}$ Homerton University Hospital, \\ London, UK
}

Keywords

Retained surgical item · Surgical drain · Endoscopy

\section{Extracção endoscópica de dreno cirúrgico retido após esofagectomia}

\section{Palavras Chave}

Itens cirúrgicos retidos · Dreno cirúrgico · Endoscopia

A 77-year-old woman with arterial hypertension and dyslipidemia reported progressive dysphagia. An upper endoscopy was performed and revealed an adenocarcinoma of the gastro-esophageal junction (Siewert type II). Computed tomography (CT) confirmed the presence of a lesion in the cardia with esophageal extension and identified celiac lymphadenopathy. She initially underwent esophageal stent placement and neoadjuvant chemotherapy. CT was repeated with no evidence of the lymphadenopathy and regression of the tumoral mass. After multidisciplinary discussion, the patient was submitted to an Ivor-Lewis esophagectomy. The patient remained asymptomatic and 12 months after the procedure, she was referred for a follow-up upper endoscopy. This exam revealed a plastic foreign body in the gastric tube lumen, partially penetrating the wall, compatible with a surgical

Rui Morais and Marco Silva contributed equally to this work.

\section{KARGER}

E-Mail karger@karger.com www.karger.com/pjg (c) 2018 Sociedade Portuguesa de Gastrenterologia

Published by S. Karger AG, Basel

Karger

Upen access

This article is licensed under the Creative Commons AttributionNonCommercial-NoDerivatives 4.0 International License (CC BYNC-ND) (http://www.karger.com/Services/OpenAccessLicense) Usage and distribution for commercial purposes as well as any distribution of modified material requires written permission. drain (Fig. 1). The patient denied dysphagia, dyspnea, chest pain, or other symptoms. The physical exam was unremarkable. She underwent a thoracoabdominal CT scan that confirmed the presence of a tubular structure in the intrathoracic portion of the gastric tube, with approximately $5 \mathrm{~cm}$ in length, attached to the surgical suture by a metal clip, without extension to the mediastinum (Fig. 2). In this case, it is possible that during the anastomosis confection by the circular suturing machine, there was a section of a surgical drain that remained attached to the surgical suture of the gastric tube. Considering that there was no evidence of esophageal perforation and the risk of surgery due to the patient's age and comorbidities, it was decided, after multidisciplinary discussion, to try to remove the surgical drain endoscopically. Upper endoscopy was then repeated and the surgical drain was removed with grasping forceps and retrieved using a snare (Fig. 3a). Gastric tube mucosa was carefully inspected revealing a congestive mucosa and self-limited bleeding in the place where the drain was previously attached, but without apparent major mucosal defects (Fig. 3b). Contrast instillation was subsequently performed, with no leakage in the fluoroscopic control. Since there was no radiographic or clinical evidence of perforation, no antibiotics were prescribed and the patient was discharged home the same day. On the follow-up, she remained asymptomatic, without evidence of complications.

Although the incidence is unknown, it is estimated that retained surgical items (RSIs) occur in 1 of 1,000 to 
1

Fig. 1. Upper endoscopy revealing a plastic foreign body material in the gastric tube lumen (arrow).

Fig. 2. Coronal view of CT scan showing a foreign body material in the gastric tube lumen, without extension to the mediastinum (arrow).

Fig. 3. a Foreign body material compatible with a surgical drain, after retrieval. b Upper endoscopy showing the site where the surgical drain was previously retained, with no evidence of complications.

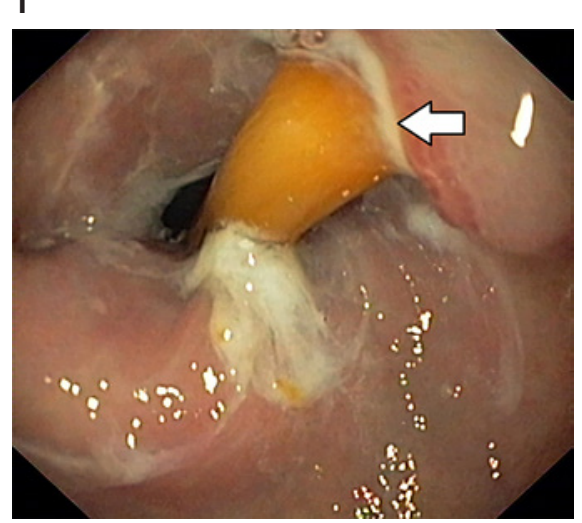

2
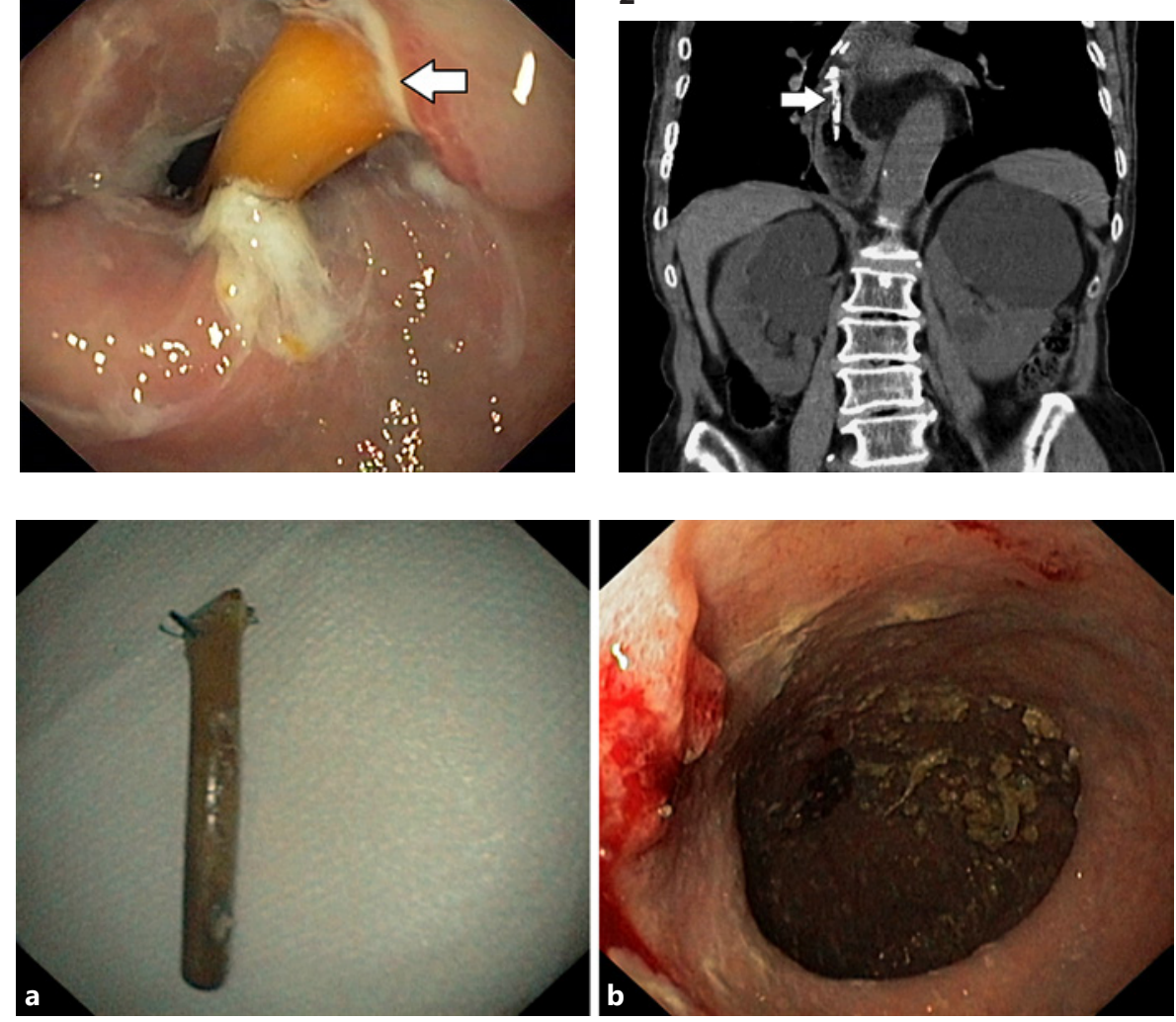

1,500 abdominal operations and approximately in 1 in every 8,000 to 18,000 of all inpatient operations $[1,2]$. Surgical sponges are the most commonly described RSIs [3]. RSIs frequently cause no symptoms but may cause severe complications [4], so they should be removed. In most cases, a surgical re-exploration is performed. However, there are scarce reports of endoscopic removal of RSIs [5]. To our knowledge, this is the first report of the endoscopic retrieval of a retained surgical drain. An additional safety measure could be the use of drains with markings in its extremities and checking it at the end of surgery. Nevertheless, this case highlights the potential role of endoscopy as a minimally invasive, safe, and effective method in selected cases of RSIs, being a reasonable alternative to open surgery.

\section{Statement of Ethics}

The authors have no ethical conflicts to disclose.

\section{Disclosure Statement}

No conflicts of interest to declare.

\section{References}

Endoscopic Extraction of a Retained Surgical Drain after Esophagectomy
1 Hyslop JW, Maull KI. Natural history of the retained surgical sponge. South Med J 1982; 75:657e660.

2 Patterson P. Preventing retained surgical items: what role does technology play? OR Manager 2009;25(1):8e11.

3 Hempel S, Maggard-Gibbons M, Nguyen DK, Dawes AJ, Miake-Lye I, Beroes JM, et al. Wrong-site surgery, retained surgical items, and surgical fires: a systematic review of sur- gical never events. JAMA Surg. 2015 Aug; 150(8):796-805.

4 Wells HA Jr, Hyun BH, Mitchell RE Jr. A retained surgical sponge with interesting sequela. Am J Med. 1963 Sep;35(3):423-6.

5 Albuquerque A, Rodrigues S, Macedo G. Video of the Month: The Colonic Tug of War: Removal of a Retained Surgical Item. Am J Gastroenterol. 2016 Feb;111(2): 174. 